\section{P1-72 STRATIFICATION OF AREA OF RISK FOR DENGUE IN METROPOLITAN AREA OF PARAGUAY}

doi:10.1136/jech.2011.142976c.65

${ }^{1}$ I Allende, ${ }^{* 1,2} \mathrm{M}$ Muñoz, ${ }^{1} \mathrm{G}$ Morel, ${ }^{1,3} \mathrm{~A}$ Cabello, ${ }^{2} \mathrm{~N}$ Martínez, ${ }^{1} \mathrm{~A}$ Ojeda, ${ }^{1}$ I Montania, ${ }^{1,3} \mathrm{M}$ Samudio, ${ }^{1} \mathrm{~K}$ Peralta. ${ }^{1}$ Dirección General de Vigilancia de la Salud, MSPyBS, Asuncion, Paraguay; ${ }^{2}$ Servicio Nacional de Erradicación de Paludismo, MSPyBS, Asuncion, Paraguay; ${ }^{3}$ Instituto de Investigaciones en Ciencias de la Salud, UNA, Asuncion, Paraguay

Dengue constitutes a severe public health problem worldwide, especially in most tropical countries where environmental conditions favour the development and proliferation of Aedes aegypti.

Objective To identify priority areas of risk in various areas creating a numerical scale designated as low, moderate or high risk.

Methodology A retrospective descriptive study was done of historical accumulated cases during the years 2006-2007, 2008-2009, 20092010. The capital city and surrounding districts were selected for the study and the following indicators were calculated: the mean incidence rates of the three epidemic periods; the general house larval infestation rate by district before the SE 14-2010 (peak of the last epidemic); and the historical movement of different serotypes in each district. Results Nine districts met the condition of population density. The average incidence rates of the three periods makes Asuncion first with 636.60 and Luque last with 167.69 per 100000 inhabitants. The house larval infestation rate is in all districts of the metropolitan area $>1 \%$. The highest is $18.46 \%$ in Fernando de la Mora and the lowest $4.94 \%$ in Mariano Roque Alonso (MRA). The history of viral circulation shows that in the metropolitan area three serotypes, DEN 1, DEN 2, and DEN 3 have circulated. In the nine Metropolitan districts, four are at moderate risk and five are at high risk.

Conclusion This epidemiological risk scale for dengue fever may be useful for the allocation of resources in a more rational way and address the actions with a risk approach.

\section{P1-73 CAN IN-HOSPITAL FATALITY RATES FOLLOWING HIP FRACTURES BE EXPLAINED? A META: REGRESSION ANALYSIS}

doi:10.1136/jech.2011.142976c.66

${ }^{1,2}$ S Alves, ${ }^{*}{ }^{1,3} \mathrm{M}$ F Pina. ${ }^{1}$ Instituto de Engenharia Biomédica, Porto, Portugal; ${ }^{2}$ Escola Superior de Tecnologia da Saúde do Porto-ESTSP, Porto, Portugal; ${ }^{3}$ Serviço de Higiene e Epidemiologia, Faculdade de Medicina da Universidade do Porto, Porto, Portugal; ${ }^{4}$ Instituto de Saúde Pública da Universidade do Porto, Porto, Portugal

Introduction The risk of death increases following a hip fracture. Objective To explain mortality rates of patients hospitalised due to hip fracture, according to multiple co-variables.

Methods A systematic review on Medline was conducted and studies were included if data for in-hospital fatality rates, following a hip fracture admission (ICD- 10 S72.0-S72.2 or ICD- 9- CM 820), was available for patients older than 50 years. Prospective cohorts were considered when appropriate data were available; experimental, review and case studies were excluded as well as studies comparing different treatments. Studies involving specific populations such as cancer or patients with kidney problems were also excluded. Studies published between 2010 and 2000 were considered. Economic, social, health and demographic data were retrieved from OECD-Organisation for Economic Co-operation and Development. A meta-regression was conducted.

Results Preliminary results lead to 21 studies selected, 15 analysed, from 11 different countries, comprising a total of 710886 cases of hip fractures. Sample sizes differ greatly between studies: 155 to 574482 Most data refers to no earlier than 1996. Data available presented heterogeneity regarding age groups, availability of information by sex and period of collection. Case fatality rates range from $0.7 \%$ in Formosa (2001) to 14\% in England (2002-2005).
Conclusions Heterogeneity observed in fatality rates could be explained by a number of variables including allocation of medical resources. Meta regression will allow knowledge incorporation, accounting for sample size and explanation of several covariates.

\section{P1-74 IS IRON INTAKE DURING EARLY PREGNANCY ASSOCIATED WITH SIZE AT BIRTH? INSIGHTS REVEALED THROUGH STRUCTURAL EQUATION MODELLING}

doi:10.1136/jech.2011.142976c.67

N Alwan, ${ }^{*}$ D Greenwood, N Simpson, J Cade. University of Leeds, Leeds, UK

Introduction Iron deficiency during early pregnancy is associated with adverse birth outcomes. Results of studies investigating the relationship between dietary iron intake during pregnancy and birth size are conflicting.

Methods We aimed to investigate the association between iron intake during pregnancy and birth size in a prospective cohort of 1274 pregnant women (18-45 years) in Leeds, UK, where iron supplements are not routinely recommended during pregnancy. Dietary intake was reported in a $24 \mathrm{~h}$ recall administered by a midwife at 12 weeks gestation. Dietary supplement intake was ascertained using dietary recall and three questionnaires throughout pregnancy.

Results $80 \%$ of women reported dietary iron intake below the UK Reference Nutrient Intake of $14.8 \mathrm{mg} /$ day. $24 \%, 15 \%$ and $8 \%$ reported taking iron-containing supplements in the first, second and third trimesters respectively. Women with dietary iron intake $>14.8 \mathrm{mg} /$ day were more likely to be older, have a university degree and take daily supplements during the first trimester. They were less likely to be smokers and live in a deprived area. Structural equation modelling was used to analyse the relationship between iron, vitamin $\mathrm{C}$ intakes and birth size taking into account socioeconomic status and smoking using Mplus software. The model showed excellent fit $\left(\chi^{2}=2.7, p=0.8, d f=5, R M S E A<0.001\right)$. The directions of the causal paths were the same as the apriori model. Conclusion The positive effect of iron status on customised birth size is influenced by both iron and vitamin C intakes. Using SEM describes the relevant relationships in a more holistic way than traditional regression modelling.

\section{P1-75 THE 2009 LEBANESE NATIONAL MAMMOGRAPHY CAMPAIGN: RESULTS AND A CRITICAL APPRAISAL}

doi:10.1136/jech.2011.142976c.68

1,2 L Kobeissi, ${ }^{2} \mathrm{R}$ Hamra, ${ }^{1} \mathrm{G}$ Samari, ${ }^{2} \mathrm{M}$ Khalifeh. ${ }^{1}$ University of California, Los Angeles, USA; ${ }^{2}$ Ministry of Public Health, Beirut, Lebanon

Introduction The Lebanese Ministry of Public Health (MoPH) has been organising subsidised annual mammography campaigns every October, since 2002, in all participating radiology centers (public and private) in Lebanon.

Methods This paper describes the characteristics of women (from all over Lebanon) attending the $2009 \mathrm{MoPH}$ mammography campaign, explores factors influencing first-time participation, and assesses the campaign's effectiveness. Data from 83 mammography centers on 10953 women (during October-December 2009) were analysed. The data were collected by the technicians, using a closed-ended structured questionnaire. Analysis revolved on descriptives, bi-variate and multivariate logistic regression.

Results The mean age of women was 49 years. $84.1 \%$ of the women were married, $13.6 \%$ had some form of university education, and $40.7 \%$ were current smokers. $82.9 \%$ had ever breast fed, $36.9 \%$ were 